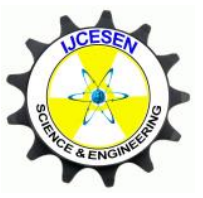

Copyright (C) IJCESEN
International Journal of Computational and

Experimental $\boldsymbol{S}$ cience and $\boldsymbol{E N g i n e e r i n g}$

(IJCESEN)

Vol. 6-No.2 (2020) pp. 78-81

http://dergipark.org.tr/en/pub/ijcesen

Research Article

\title{
Study of the Influence of Cementation Layer Thickness on Properties of Chromium Carbide Obtained by Conversion Treatment
}

\section{Rabah BOUBAAYA ${ }^{1,2^{*}}$, Omar ALLAOUI ${ }^{1}$, Mokhtar DJENDEL ${ }^{1,2}$, Younes BENARIOUA ${ }^{3}$, Zied DRISS ${ }^{4}$}

\author{
${ }^{1}$ Laboratoire de Génie des procédés, Université Amar Telidji - Laghouat, Algeria \\ ${ }^{2}$ Département des Sciences et Techniques, Faculté des Sciences et de la Technologie, Université de Bordj Bou \\ Arreridj, 34000, Bordj Bou Arreridj, Algeria \\ ${ }^{3}$ Département de Génie Mécanique, Faculté de la Technologie, Université de M'sila, Algeria \\ ${ }^{4}$ Laboratory of Electro-Mechanic Systems (LASEM), National School of Engineers of Sfax (ENIS), Tunisia
}

* Corresponding Author : raboubaaya@yahoo.fr ORCID:0000-0002-3672-3185

\section{Article Info:}

DOI: $10.22399 /$ ijcesen.692070

Received : 22 February 2020

Accepted : 24 April 2020

\section{Keywords}

Steel

Carbon

Chromium

Layer

Cementing

Chromium carbide

Diffusion

Precipitation

Deposition

\begin{abstract}
:
Steel substrates low carbons were face-hardened by cementing in case, and then thin layers of chromium were deposited by electrolytic way on these substrates. After deposition, the samples were exposed to isothermal annealing in the temperature of $950^{\circ} \mathrm{C}$. The characterization of the thin layers was made by means of optical microscopy and interferometry Vickers micro-hardness. From the obtained results, we have established the kinetics of phase shift (under effect the layer of cementing) in the thin layers of chromium which are transformed into chromium carbide while passing by metastable phases of transition. These transformations occurred by diffusion of the carbon atoms coming from layer of cementing, germination and growth in solid phase. This fact has examined according to the temperature of annealing, the evolution of the lattice parameter and the morphology of the deposited chromium layer. As regards the mechanical properties, it was established that the micro-hardness believes with the evolution of the phase shift.
\end{abstract}

\section{Introduction}

Over the past two decades, the transition metal carbides of the coatings were found to be one of the most effective materials for increasing the life time of the machine components, cutting tools and forming tools, in particular to improve wear and corrosion resistance [1,2]. Among these metal compounds, chromium carbide has the best mechanical and chemical resistance in harsh conditions. Recent research on chromium carbide stressed their resistance to oxidation and corrosion and suggested that they have great potential to replace hard chrome electroplating as protective coatings $[3,4]$. The chromium carbide layers can be obtained by physical vapor deposition (PVD) $[5,6]$ or thermo-reactive deposition/diffusion (TRD) technology $[7,8]$. In the case of PVD thickness is much less than $10 \mu \mathrm{m}$ making those unfit also withstood the high contact pressure and further adhesion to the substrate is less than that obtained with other types of coating techniques. TRD coatings must very long process times at high temperatures. For example, a thickness $8 \mu \mathrm{m}$ chromium carbide layer was obtained on a steel AISI D2 with a treatment at $1030^{\circ} \mathrm{C}$ for $4 \mathrm{~h}$ [9] and a thickness of $13 \mu \mathrm{m}$ was obtained with treatment at $1000{ }^{\circ} \mathrm{C}$ for $3 \mathrm{~h}$ [10]. Indeed, there are very common industrial methods that can be combined in any manner to produce chromium carbide coatings.

In order to produce a high-hardness coating, a good adhesive properties and a sufficient thickness with stand severe loading conditions, we propose an alternative technique based on a three-step process using only standard industrial methods. The first step intends to increase the carbon content at the 
surface of the substrate using a standard carburizing process. The second step consists to coat the carburized material with a layer of chromium. The final step considers the heat treatment at temperatures which allow the diffusion of carbon into the surface of the material. In this work, we propose to determine the experimental conditions which allow complete conversion of the chromium layer in a uniform layer of high hardness of chromium carbide and a good adhesion to the substrate.

\section{Experimental methods}

\subsection{Materials and coating deposition}

Cylindrical steel samples were selected of $20 \mathrm{~mm}$ in diameter and $15 \mathrm{~mm}$ in length. The chemical composition of the substrate reported in Table 1 was determined by spectrometric analysis using a spectrometer HILGER.

Table 1. Chemical composition of steel to be coated (\%).

\begin{tabular}{|l|l|l|l|l|l|l|}
\hline Fe & $\mathbf{C}$ & $\mathbf{S i}$ & $\mathbf{M n}$ & $\mathbf{P}$ & $\mathbf{S}$ & $\mathbf{C r}$ \\
\hline 95.99 & 0.19 & 0.22 & 0.94 & 0.003 & 0.056 & 1.12 \\
\hline $\mathbf{M o}$ & $\mathbf{N i}$ & $\mathbf{A l}$ & $\mathbf{C o}$ & $\mathbf{C u}$ & $\mathbf{T i}$ & $\mathbf{S n}$ \\
\hline 0.07 & 1.18 & 0.0116 & 0.01 & 0.20 & 0.0012 & 0.010 \\
\hline
\end{tabular}

The preparation of the substrate consists on a mechanical polishing on each sample using abrasive papers. The finishing operation provides a good polishing with felt washed down with a suspension of alumina in water. The polished surface must be cleaned thoroughly with water and dried with compressed air and hot filtered. To conduct a comparative study, we divided the samples into 4 groups as is reported in Table 2.

Cementing is performed using a cement coke powder. To accelerate cementing process, barium carbonates $\mathrm{BaCO}_{3}$ is added to coal activators.

Table 2. Carburizing test parameters.

\begin{tabular}{|c|c|c|c|c|}
\hline Group & I & II & III & IV \\
\hline Hold time & 00 & 03 & 06 & 12 \\
hours & hours & hours \\
\hline $\begin{array}{c}\text { Cementing } \\
\text { thickness }\end{array}$ & $\begin{array}{c}\mathrm{E} 1= \\
00 \\
\mathrm{~mm}\end{array}$ & $\begin{array}{c}\mathrm{E} 2=0.6 \\
\mathrm{~mm}\end{array}$ & $\begin{array}{c}\mathrm{E} 3=1.3 \\
\mathrm{~mm}\end{array}$ & $\begin{array}{c}\mathrm{E} 4=2.5 \\
\mathrm{~mm}\end{array}$ \\
\hline Temperature & & $900^{\circ} \mathrm{C}$ & $900^{\circ} \mathrm{C}$ & $900^{\circ} \mathrm{C}$ \\
\hline
\end{tabular}

Samples were chrome electroplating, the standard composition of plating bath: $250 \mathrm{~g} / 1 \mathrm{CrO}_{3}, 2.5 \mathrm{~g} / 1$ $\mathrm{SO}_{4} \mathrm{H}_{2}$, bath temperature $\left(40-44{ }^{\circ} \mathrm{C}\right)$, antimony lead anode, retention time 0.5 hour and deposition rate of about $40 \mu \mathrm{m} / \mathrm{h}$.

In order to obtain a layer of chromium carbide, chromium coated samples were a thermal annealing treatment in the temperature of $950{ }^{\circ} \mathrm{C}$. The hold time is taken 1 hour.

\subsection{Characterization and analysis techniques}

Microscopic observation requires fine polishing of the surface or the cutting of the deposit to be observed. Cleaning with acetone and drying by hot air flow end the mechanical polishing. The second phase consists of a chemical attack using the product nital, the composition and proportions by volume are nitric acid $(5 \mathrm{ml})$ and ethanol $(95 \mathrm{ml})$. Chemical etching can reveal the different phases presenting the optical microscope. The equipment used is a universal optical metallographic microscope ZEISS type.

The micro Vickers hardness test allows us to measure the size of the indentation made on the deposit. Measurements of the micro hardness of the deposits have been made on surfaces of polished sections. The indentations under a load of 50 grams were made through a microdurometer type Buehler MICROMET (HARDNESS TESTER) which is equipped with a Vickers diamond indenter. The samples have been tested in the Vickers microhardness with five measurements on each sample. Considering the average value obtained over five fingerprints to reduce measurement errors.

\section{Results and discussion}

\subsection{Morphology}

Figure 1 shows the observation of metallographic faces layer/substrate after annealing at $950{ }^{\circ} \mathrm{C}$. From these results, it has been observed that no chromium carbide trace could be revealed in the pictures corresponding the sample without cementation $\left(e_{1}=0 \mathrm{~mm}\right)$. The sample of group II $\left(\mathrm{e}_{2}=0.6 \mathrm{~mm}\right)$, a chromium carbide edge occurs in the vicinity of the interface. This fact is reflected by the low diffusion of carbon cementation zone in the deposited chromium layer. In the picture corresponding to the sample of group III $\left(e_{3}=1.3\right.$ $\mathrm{mm}$ ), it has been noted that the microstructure is predominantly in chips arranged on the substrate surface. This kind of morphology is found in several cases of phase change in the solid state. The structure of the incipient phase is usually in the form of needles certain plane oriented parallel to the surrounding parent phase. Increasing the amount of carbon diffusion from the substrate causes a progressive propagation of chromium carbide in the deposition of chromium. For the sample of group IV $\left(\mathrm{e}_{4}=2.5 \mathrm{~mm}\right)$, chromium matrix is transformed completely to chromium carbides. The formed layer has a granular structure. The morphology of the deposit of chromium carbides mainly depends on the treatment temperature, which promotes the mobility of atoms in the layer and the substrate. Mobility supports 


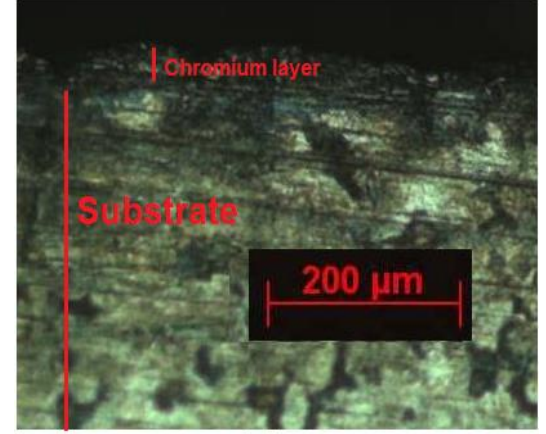

(a)

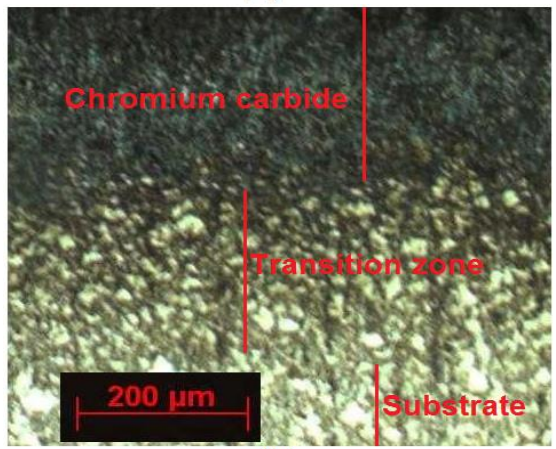

(b)

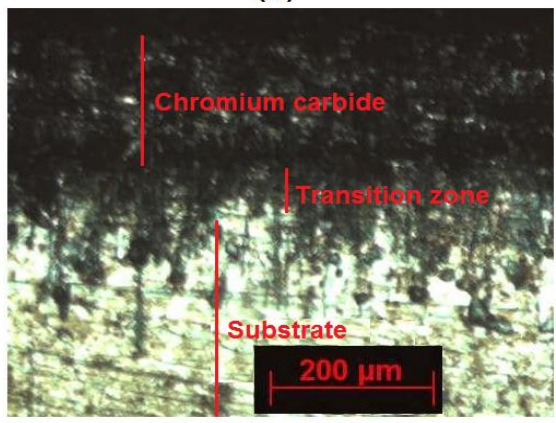

(c)

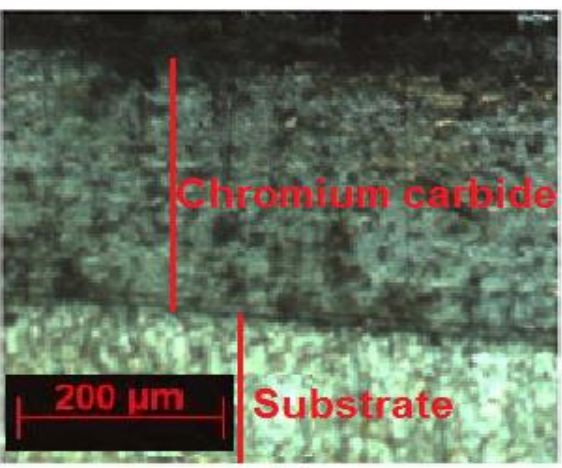

(d)

Figure 1. Observation of metallographic faces layer/substrate after annealing at $950{ }^{\circ} \mathrm{C}$ : (a) the sample of group I $\left(e_{1}=0 \mathrm{~mm}\right)$, (b) the sample of group II $\left(e_{2}=\right.$ $0.6 \mathrm{~mm}),(\mathrm{c})$ the sample of group III $\left(e_{3}=1.3 \mathrm{~mm}\right),(d)$ the sample of group IV $\left(e_{4}=2.5 \mathrm{~mm}\right)$.

traverses the diffusing carbon element concentration from the substrate to the layer.

Indeed, the thickness of the carburized layer presents a great effect on the chromium conversion rate into chromium carbides.

\subsection{Hardness}

Fig.2. shows the effect of the thicknesses of the carburizing layer on the micro-hardness. According

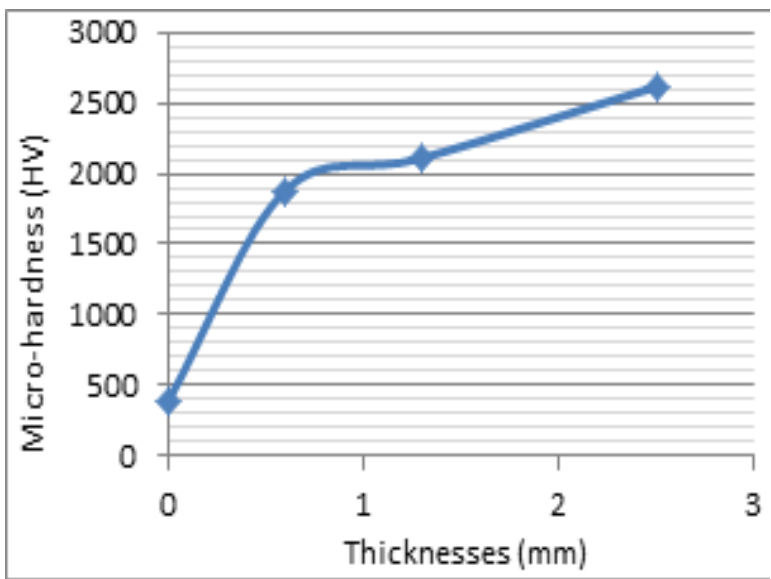

Figure 2. Effect of carburizing layer thicknesses on micro-hardness.

Table 3. Change in micro-hardness depending on the thicknesses of the carburizing layer.

\begin{tabular}{|c|c|}
\hline $\begin{array}{c}\text { Thicknesses of the } \\
\text { carburizing layer }\end{array}$ & $\begin{array}{c}\text { Micro-hardness } \\
\text { (HV) }\end{array}$ \\
\hline $\begin{array}{c}\mathrm{e}_{1}=0 \mathrm{~mm} \\
\text { Without cementation }\end{array}$ & 390 \\
\hline $\mathrm{e}_{2}=0.6 \mathrm{~mm}$ & 1880 \\
\hline $\mathrm{e}_{3}=1.3 \mathrm{~mm}$ & 2110 \\
\hline $\mathrm{e}_{4}=2.5 \mathrm{~mm}$ & 2615 \\
\hline
\end{tabular}

to these results, it is clear that the micro-hardness still is evolving in ascending order. Micro-hardness measurements made on samples $\mathrm{e}_{3}$ and $\mathrm{e}_{4}$ show that the micro-hardness is even greater than that of the samples $e_{1}$ and $e_{2}$ as it is shown in Fig.2 and reported in Table 3.

Curing would be linked to the complete formation of the chromium carbide that will cause a reinforcing of deposits. Diffusion of carbon atoms reaches the outer surface of the layer; the atoms occupy the chromium surface interstices; for thus, it will be a total loss of chromium phase.

In these conditions, the thicknesses of the carburizing layer $\mathrm{e}_{2}, \mathrm{e}_{3}$ and $\mathrm{e}_{4}$ are equal to: $0.6,1.3$ and $2.5 \mathrm{~mm}$, respectively. From these results, we can confirm that the difference between the cementation thicknesses may cause difference in micro-hardness.

\section{Conclusion}

In this paper, we are interested on the increasing of the performance steels chromium carbide creation with high features. For thus and after carburizing 
and deposition by electroplating, a chromium layer on the steel samples (layer/substrate) were subjected to annealing at $950^{\circ} \mathrm{C}$. In this temperature, the deposited film is gradually converted to chromium carbide. Phase transformation which took place primarily by diffusion of the substrate carbon atoms in the layer was determined by metallographic analysis. The hardness of the produced layers evolved following the thickness of the carburized layer. The obtained value is in agreement with the changing properties determined by microscopic observation.

Indeed, it has been noted that for sample without cementation $\left(e_{1}=0 \mathrm{~mm}\right)$, thin films retain their monophasic character, micro-hardness of the deposited raw layer is larger than that treated. It should be noted that for the sample of group II $\left(\mathrm{e}_{2}=\right.$ $0.6 \mathrm{~mm})$ and the sample of group III $\left(\mathrm{e}_{3}=1.3 \mathrm{~mm}\right)$, the incipient phase is increased while the chromium mother phase undergoes a decrease. This causes a high hardening of the obtained deposit. For the sample of group IV $\left(\mathrm{e}_{4}=2.5 \mathrm{~mm}\right)$, the chromium layer is completely converted into chromium carbides that would be responsible for the increase of the hardness.

In this case, it is both the thicknesses of the layers of carburization temperature treatment which play an essential role in the transformation of the chromium layer to chromium carbides.

\section{References}

[1] K. Hirota, K. Mitani, M. Yoshinaka, O.Yamaguchi, Simultaneous synthesis and consolidation of chromium carbides $\left(\mathrm{Cr}_{3} \mathrm{C}_{2}, \mathrm{Cr}_{7} \mathrm{C}_{3}\right.$ and $\left.\mathrm{Cr}_{23} \mathrm{C}_{6}\right)$ by pulsed electric-current pressure sintering, Materials Science and Engineering A 399 (2005) 154-160. DOI:10.1016/j.msea.2005.02.062

[2] C. Y. Wei, F. S. Chen, Thermoreactive deposition /diffusion coating of chromium carbide by contactfree method, Materials Chemistry and Physics 91 (2005)192-199.

DOI:10.1016/j.matchemphys.2004.11.010

[3] N. Syla, F. Aliaj, B. Dalipi, The law of growth of nitrided layer in 31CrMoV9 steel, Acta Physica Polonica A $130 \quad$ (2016) 83-86. DOI:10.12693/APhysPolA.130.83

[4] G. Herranz, G. Matula, A. Romero, Effects of chromium carbide on the microstructures and wear resistance of high speed steel obtained by powder injection moulding route, Powder Metallurgy 60 (2017)120-130. DOI:10.1080/00325899.2017.1288778

[5] İ.H. Karahan, F. Tiltil, Electrodeposition and corrosive properties of environmental $\mathrm{ZnFe}$ /polyaniline on low carbon steel, Acta Physica Polonica A 130 (2016) 282-285.

DOI: 10.12693/APhysPolA.130.282.
[6] M. Petrovic, A. Voloder, Flexural strength reduction in cemented carbides, Acta Physica Polonica A $128 \quad$ (2015) B23-B25. DOI:10.12693/APhysPolA.128.B-23

[7] M. Davraz, The effect of boron compound to cement hydration and controllability of this effect, Acta Physica Polonica A 128 (2015) B26-B33. DOI: 10.12693/APhysPolA.128.B-26

[8] K. Natesan, R.N. Johnson, Corrosion resistance of chromium carbide coatings in oxygen-sulfur environments, Surface and Coatings Technology. 33 (1987) 341-351. DOI:10.1016/0257-8972(87)90200-3

[9] A. Akkas, A.B. Tugrul, B. Buyuk, A.O. Addemir, M. Marsoglu, B. Agacan, Shielding effect of boron carbide aluminium metal matrix composite against gamma and neutron radiation, Acta Physica Polonica A 128 (2015) B176-B179.

DOI: 10.12693/APhysPolA.128.B-176

[10] J. E.G. Ruíz, A. R. Cristo, A. P. Ramos, R. Q. Puchol, Deposition of multicomponent chromium carbide coatings using a non-conventional source of chromium and silicon with micro-additions of boron, Materials Research 20 (2017) 168-174. DOI: 10.1590/1980-5373-mr-2016-0308. 